The Research Journal of the Costume Culture

[Original Article]

Received April 03, 2017

Revised April 21, 2017

Accepted April 26, 2017

${ }^{\dagger}$ Corresponding author

(yoheunah@kmu.ac.kr)

ORCID

Eunah Yoh

http://orcid.org/0000-0003-2894-0283

The present research has been conducted by the Bisa Research Grant of Keimyung University in 2014.

\section{Victim personality and appearance factors affecting bullying of middle school students and a model of consequence variables}

\author{
Eunah Yoh $^{\dagger}$ \\ Dept. of Fashion Marketing, Keimyung University, Korea

\section{중학생 집단 따돌림에 영향을 미치는 피해자의 성격 및 외모 요인과 후행변인 관계모형}

\author{
여 은 $\mathrm{OP}^{+}$
}

계명대학교 패션마케팅학과

\begin{abstract}
In this study, causes and consequences of bullying were explored, focusing on victim personality and appearance factors. The research model included the relationships among bullying, important causes of bullying (aggression, cleanliness, and obesity of victims) and consequences of bullying (self-esteem and depression) and was tested through survey data from 594 (194 male and 404 female) middle school students. Data were analyzed using descriptive statistics, confirmatory factor analysis, and path analysis with SPSS and AMOS. In the results of the model tests, victims who are more aggressive, less clean, and more overweight are more likely to be bullied. In addition, adolescents bullied by others tend to have lower self-esteem and more depression. Furthermore, the model comparison was assessed by gender and a difference between the two gender models was found. In the check of critical ratio for difference, it was concluded that the cleanliness of the victim is a more important cause of bullying for male adolescents than for female adolescents. It is meaningful to confirm the effects of the victim's appearance factors on bullying in the literature focusing on personality issues of victims. Educators and counselors may refer to the findings in developing counseling guidelines and manuals to prevent bullying in school.
\end{abstract}

Keywords: aggression(공격성), cleanliness(청결성), obesity(비만), bullying(집단따돌 림), self-esteem(자아존중감)

\section{Introduction}

집단따돌림과 동료 학생들의 괴롭힘에 못 이겨 스스로 목숨을 끊는 사고가 잇따 르면서 학생들의 집단따돌림에 대한 관심이 높다. 최근 암을 이겨내고도 일그러진 입모양 때문에 급우들로부터 집단따돌림을 당하다 자살을 택한 미국 여중생의 소 
식은 이러한 문제의 심각성을 크게 일깨워주었다 (Shin, 2016). 우리나라에서 '집단따돌림' 문제가 본 격적으로 대두되기 시작한 것은 1997년으로, 한 여중 생이 집단따돌림으로 인해 자살한 사건이 그 발단이 되었다(Chung, 2011). 특수교육학사전에 따르면 '집 단따돌림'은 “가해 학생과 피해 학생의 힘의 불균형 에서 발생하는 부정적 행동으로, 폭행, 위협, 못살게 굴기, 놀리기, 소외시키기 등을 포함하는 포괄적 행 동”으로 정의된다(“Bullying”, 2009).

집단따돌림 문제는 소수만의 문제가 아니며, 도시 화와 더불어 교육, 문화 환경변화에 의해 그 범위가 더욱 확대되어가고 있는데, Kim and Chung(2007)에 따르면 조사대상 청소년의 $39 \%$ 가 지난 1 년간 집단따 돌림을 경험한 것으로 나타났다. 집단따돌림은 우리 나라만의 문제가 아니며, 미국, 유럽, 일본, 대만 등에 서도 심각한 사회문제로 여겨지고 있다(Andreou \& Bonoti, 2010; Wei \& Johnson-Reid, 2011; Yoo \& Johnson, 2007). 북아일랜드의 조사에서는 응답자의 $40 \%$ 가 집단따돌림의 피해를 본적이 있다고 답하였으 며(Mc Guckin, Cummins, \& Lewis, 2008), 미국의 경 우 15세부터 24세 사이 학생 중 6,000 여명이 매년 따 돌림과 관련된 문제로 자살하며, 미국인의 $1 / 3$ 은 학 창시절 중 어떤 유형으로든 따돌림을 경험한 적이 있 다고 한다(Overseas Economic Team, 2017).

집단따돌림의 피해는 학교활동 기피, 학업성취도 저하, 자기존중감 하락, 우울감 증대 등으로 이어지 며, 심할 경우 자퇴, 자살 등으로까지 이어질 수 있으 므로(Gini, 2008; Ranta, Kaltiala-Heino, Pelkonen, \& Marttunen, 2009) 집단따돌림이 왜 일어나는지 그 원 인 파악이 매우 중요할 것이다. 청소년들은 가해자의 문제보다는 피해자의 특성 요인이 집단따돌림의 가 장 큰 원인이라고 지목하고 있다(Kim, 2005). Koo (1997)는 집단따돌림 피해자를 크게 수동적 피해자 (passive victim)와 공격적 피해자(provocative victim) 의 두 가지 유형으로 구분하였는데, 수동적 피해자는 외모가 단정하지 못하거나, 신체적으로 남과 다르거 나 신체적 열세를 가지고 있는 경우가 많다고 하였으 며, 공격적 피해자는 과잉행동이나 공격성을 내재하 고, 자기애가 강한 편이라고 하였다. 이를 바탕으로 집단따돌림 피해자 특성 중 외모적 특성과 공격적 성 격 특성이 잡단 따돌림을 유발하는 영향 요인이라 가
정할 수 있으며, 외모적 특성 중 비만과 청결성은 자 주 제시되는 피해자 특성 요인이었다(The Korean Federation of Teachers' Association, 1999).

집단따돌림에 대한 문제가 날로 심각해져가는 상 황에서 피해자 성격 요인(공격성)과 외모 요인(청결 성, 비만도)이 중학생의 집단따돌림 피해에 직접적인 영향을 미치는 요인인지를 알아보고, 이러한 집단따 돌림이 사회심리학적(자아존중감), 병리학적(우울감) 으로 어떤 결과를 낳는지에 대한 실증자료를 제시함 으로써 교육지도와 후속 연구에 활용 가능한 시사점 을 얻고자 한다. 집단따돌림의 피해자 특성 요인에 있어 외모 요인이 중요함에도 불구하고, 사회학이나 심리학 분야의 선행연구에서는 피해자의 외모보다는 성격 요인에 집중하여 연구해 왔으며, 외모요인의 영 향에 대한 실증연구가 매우 미흡했다. 의류학 분야에 서는 청소년기가 의복과 외모를 통해 자신과 타인을 판단하는 경향이 높은 시기이며, 외모 요인이 또래관 계 형성과 정신건강 및 심리적 발달에 매우 중요하게 영향을 미치는 시기라 여기고, 오랫동안 관련 연구들 을 진행해 왔으나(Lee, 2009), 이를 집단따돌림과 연 관시켜 진행한 연구 노력은 부족했다. 본 연구에서는 피해자 외모 요인을 집단따돌림 유발의 중요한 영향 요인으로 지목하고, 이를 중심으로 집단따돌림의 선 ·후행 변인과의 관계에 대한 실증적 검증을 하고자 한다.

\section{Literature Review}

\section{Bullying of the juvenile and characteristics of victims}

청소년기는 12 14세까지 전기, 15 18세까지 후 기 청소년기로 구분되는데(Samples \& Aber, 1998), 이 중 또래집단의 영향력이 최고조에 달하며, 학교 비행 등에 상대적으로 더 많이 노출되어 있는 것이 청소년 전기, 즉 중학생들로 폭력예방재단 상담 자료 에 따르면 집단따돌림의 $59 \%$ 가 중학교에서 발생된다 (Kim, 2005). 집단따돌림 행동에는 때리기, 밥 못 먹 게 하기, 넘어뜨리기, 소지품 훔치기, 심부름시키기 등의 신체적 괴롭힘과 이유 없이 욕을 하고 무시하 며, 따돌리는 관계적 괴롭힘이 있는데, 남자 청소년이 여자 청소년에 비해 더 자주 집단따돌림에 관여한다 
고 알려져 있다(Andreou \& Bonoti, 2010). 남학생은 주로 신체적 괴롭힘을, 여학생은 주로 관계적 괴롭힘 을 하는 등 성별에 따라 다른 양상을 보인다고 주장된 바 있다(Craig et al., 2009; Skraypiec, Slee, MurrayHarvey, \& Pereira, 2011).

The Korean Federation of Teachers' Association (1999)이 발표한 자료에 따르면 집단따돌림을 당하는 청소년 피해자의 특성 중 내성적인 성격, 이기적이고 잘난 척하는 성격, 공격적이거나 산만한 성격 등 성 격 특성과, 외모와 관련하여 비만하여 동작과 태도가 둔함, 단정하지 않은 용모와 불청결함 등 외모적 특 성이 제시되었다. Moon(2014)의 연구에서도 자기표 현 능력이 부족하고 부적절한 공격행동을 하거나, 신 체적으로 너무 뚱뚱하거나, 못생겼거나, 신체가 약하 거나 하는 특징을 가진 경우 집단따돌림의 피해를 입 을 가능성이 있다고 하였다.

이러한 자료들을 종합해볼 때 피해자 특성 요인으 로 자주 제시되고 있는 성격 요인은 공격성(Chung, 2009; Olweus, 1994)인데, 공격성이 높은 아이들은 집단따돌림의 피해를 받은 후, 다시 집단따돌림의 가 해자로 전환될 가능성이 높다고 할 수 있다(Lee, 1999). 성격 특성 외에 외모 요인도 집단따돌림 피해 자 특성으로 자주 지적된다. 2010년 통계청에서 발표 한 “사회조사보고서”에 따르면 15 24세 연령층이 가장 고민하는 문제는 성적, 직업선택과 함께 외모가 가장 큰 부분을 차지하고 있는 것으로 확인되었다 (Statistics Korea, 2010). 미국에서도 12세 여학생이 외모에 대한 친구들의 괴롭힘 때문에 자살하는 사건 이 있었으며, 외모에 대한 괴롭힘을 견디다 못한 학 생이 총기로 2 명을 죽이고, 13 명을 다치게 한 사건까 지 발생하였다(Yoo \& Johnson, 2007). Lee and Kim (1999)은 따돌림을 당하는 아이들 중에는 비만하거 나, 키가 지나치게 작거나, 못생긴 아이 등 신체적 약 점을 가진 아이들이 다수 포함된다고 설명하였다. 실 제로 울산의 한 여학생은 못생겼다는 이유로 따돌림 을 당해 괴로웠다는 유서를 남기고, 자기 방에서 교 복 넥타이로 목을 매 숨지는 등(Lee, 1995), 외모관련 집단따돌림의 피해사례가 도처에서 발견되고 있음에 도, 구체적으로 어떠한 외모관련 요인이 집단따돌림 에 영향을 미치는지에 대한 실증적 연구노력은 부족 하였다.
외모 요인 중 비만은 자아존중감에 큰 영향을 미치 는 요인으로 여겨지는데, National Youth Policy Institute(2010)에서 실시한 청소년 비만실태조사에서 청소년 비만은 자아존중감, 우울감 등에 부정적인 영 향을 미치는 것을 파악하였다. 최근 몇몇 학자들은 비 만이 집단따돌림의 원인이 될 수 있다고 지적했지만 (Barnett, Livengood, Sonnentag, Barlett, \& Witham, 2010; Lumeng, Castle, \& Lumeng, 2010), 이에 대한 실증적 연구는 부족했다. 비만 외에도 청결도는 따돌 림 피해 학생 특성 중 자주 언급되는 요인이다. The Foundation for Preventing Youth Violence(1999)가 발표한 ‘왕따 극복하기 지침서'에 따르면 잘 씻지 않 거나 복장이 지저분한 학생, 즉 청결하지 못한 학생 이 따돌림을 받기 쉬운 학생이라고 제시되었다. 이러 한 선행연구들을 바탕으로 다음과 같은 가설을 제시 한다.

가설 1. 공격성이 높을수록 집단따돌림을 더 많이 당할 것이다.

가설 2. 청결도가 낮을수록 집단따돌림을 더 많이 당할 것이다.

가설 3. 비만도가 높을수록 집단따돌림을 더 많이 당할 것이다.

\section{Consequences of bullying}

청소년기에 있어서 친구는 자기 가치감의 증진, 스 트레스 완화 역할을 하며, 또래 수용은 자아존중감에 매우 중요한 영향을 미친다. 자아존중감이란 타인으 로부터 인정받기 위해 자신에 대한 가치를 얼마나 높 게 평가하는가와 관련된 개념으로(Mussen, Conger, Kagan, \& Huston, 1984), 청소년 시기에 자아존중감 이 높으면 자신에 대한 믿음을 가지고 긍정적으로 문 제 상황에 대처할 수 있으므로 긍정적 정서 형성이 가능하다(Seo, 2003). 청소년 시기에는 친구와의 교류 를 통해 자신에 대해 통찰하고, 자아존중감을 발전시 키는데(Kim, 2000), 이 시기에 집단따돌림의 원인 등 으로 교우간의 긍정적 관계형성이 어려우면 자아존 중감에도 부정적 영향을 미칠 것으로 예측할 수 있다. 또래의 지속적인 비난과 괴롭힘은 그 당시의 자존감 에 부정적 영향을 미칠 뿐만 아니라, 성인이 될 때까 지 그 여파가 계속 남아 성인기의 자아의식에도 부정 
적 영향을 미친다(Lund et al., 2009; Sweetingham \& Waller, 2008). 집단따돌림을 당한 이후 본인에 대한 느낌을 묻는 질문에 대해 외롭다 $(50.4 \%)$, 억울하다 (39.6\%)는 답변 외에도 자신에 대해 화가 난다 (45.5\%), 나의 못남이 싫다 $36 \%)$ 등(Kim \& Park, 1997), 자학적 느낌이 많아 자아존중감에 영향을 줄 수 있는 여지가 충분한 것으로 여겨진다. 실증연구에 서도 Olweus(1994)는 집단 괴롭힘 정도와 자아존중 감 사이에 부(-)의 상관성을 발견하였다.

집단따돌림의 피해는 자아존중감에 뿐만 아니라, 우울감 증대에도 영향을 미치며, 심할 경우 자퇴, 자 살 등으로까지 이어진다고 알려져 있다(Gini, 2008, Ranta et al., 2009). 집단따돌림 피해 청소년들은 자 기 패배적 사고를 가지고 불안감과 우울감이 높은 경 향이 있는데(Moon, 2014), 집단따돌림 피해도가 높을 수록 불안과 우울수치가 높게 나타남이 확인된 바 있 다(Choi, 2009). 한편, 낮아진 자아존중감은 다시 우 울감에 유의한 영향을 미치는 것으로 확인되었는데 (Callaghan \& Joseph, 1995; Lee, 2003), 청소년기에 있어 자아존중감과 우울감 사이의 부적관계는 또 다 른 연구(Jeong, 2013)에서도 확인된 바 있다. 이러한 선행연구를 바탕으로 제시한 가설은 다음과 같다.

가설 4. 집단따돌림을 더 많이 당할수록 자아존중 감은 더 낮아질 것이다.

가설 5. 집단따돌림을 더 많이 당할수록 우울감은 더 높아질 것이다.

가설 6. 자아존중감이 더 낮을수록 우울감은 더 높 을 것이다.

\section{Gender difference in research variables}

집단따돌림과 이의 선·후행 변인에 대한 성별 차 이 연구는 활발히 행해지지 않았다. 발견된 몇 개의 연구에 따르면, 우리나라 중학생들을 대상으로 집단 따돌림의 피해경험 수준을 비교한 연구에서 여학생 이 남학생보다 집단따돌림 피해경험이 더 많다는 조 사결과와(The Foundation for Preventing Youth Violence, 1999), 남학생의 집단따돌림 피해 경험이 더 많다는 결과가 혼재되어 나타난다(Kim \& Koo, 2016). 이는 신체적 따돌림과 관계적 따돌림을 포함하는 집 단따돌림의 범위와 정도에 대한 개념 인식에 개인 차
이가 많아 나타난 결과로 생각할 수 있다.

한편, 청소년기의 자아존중감은 사춘기에 접어드 는 중학시절에 낮아지는데, 여자 청소년이 남자 청소 년보다 더 낮은 자아존중감을 가진다는 보고가 있다 (Jacobs, Lanza, Osgood, Eccles, \& Wigfield, 2002). 고등학생 집단을 대상으로 한 조사에서도 여학생 집 단은 남학생 집단보다 더 낮은 자아존중감으로 보였 다(Kim, Kim, \& Kim, 2002). 우울감에 대한 성별차 이 연구에 따르면 남성보다 여성의 우울감이 높은 경 향이 있는데, 이는 슬픔이나 불안 등 여성들이 남성 들보다 부정적 감정을 공개하는 경향이 높고, 그에 반해 남성은 강인해야 한다는 사회적 압박 속에서 이 를 표현하는 것에 소극적이기 때문일 것으로 예측되 어 왔다(Leahy, Holland, \& McGinn, 2011). 청소년기 에도 여자 청소년이 남자 청소년보다 우울감 수준이 더 높은 것으로 나타나는데, 청소년 건강행태조사 결 과(Centers for Disease Control \& Prevention, 2014) 에 따르면 여학생의 $31.6 \%$ 와 남학생의 $22.2 \%$ 가 우울 감을 느끼고 있다고 하여 우울감을 느끼는 여학생이 더 많은 것을 알 수 있다.

청소년의 성격 특성 중 공격성은 다른 사람에게 의 도적으로 심리적 혹은 신체적 해를 끼치려는 행위라 고 설명될 수 있다(Brehm \& Kassin, 1990). 공격성은 중학교 시기인 13 세부터 15 세 사이에 증가하다가 그 이후에는 정서적, 신체적 성숙으로 인해 점차 감소하 는 경향을 보인다(Loeber \& Stouthamer-Loeber, 1998). 선행연구에서 전통적으로 여성에 비해 남성의 공격 성이 더 높은 것으로 확인되었으며, 이는 미성년의 경우 그 격차가 더 크다고 알려져 있다(Archer, 2004). 한편, 공격성의 하위요소별로 나누어 볼 때 신체적 공격성은 남성이 여성보다 더 높지만, 따돌린다던가 나쁜 소문을 퍼뜨린다던가는 관계적 공격성은 여학 생에서 더 높은 것으로 나타났다(Sim, 2007). 청소년 패널자료를 가지고 검증한 연구에서는 중학생 집단 의 경우, 여학생이 남학생보다 더 높은 공격성을 가 진 것으로 보고되어(Lee, $\mathrm{Wi}, \& \mathrm{Kim}, 2015)$ 성별차 이에 대한 결과가 혼재되어 나타나는 것을 알 수 있다.

청소년의 외모적 특성 중 비만도 면에서 성별 차이 를 발견한 선행연구들이 있는데, 남녀 고등학생 집단 을 비교한 결과에 따르면 남학생 집단이 여학생 집단 에 비해 체질량지수가 더 높게 나타났으나, 주관적 
비만평가에서는 여학생이 남학생보다 자신이 비만하 다고 평가하는 경향이 높은 것으로 나타나, 다소 대 치되는 결과를 보였다(Kim et al., 2002). 청결성에 대 한 성별비교 연구는 적은 편이었는데, 초등학교 3 6 학년을 대상으로 한 연구에서 여학생 집단의 신체 및 의복 청결성이 남학생 집단보다 더 높게 나타난(Park \& Chung, 2014) 연구 외에 청결성의 성별차이에 집 중한 연구는 발견하기 어려웠다.

각 특성요소에 대한 성별차이를 본 연구도 적은 편 이었지만, 청소년의 성별에 따라 성격 특성과 외모 특성이 집단따돌림에 미치는 영향에 대한 차이를 본 연구는 발견되지 않았다. 그러나 청소년기에 남녀 성 별에 따른 신체적, 정서적 차이가 뚜렷해지는 시기이 며, 의식과 행동면에서 차이를 보이는 시기이므로, 각 연구변인 값과 연구변인간의 관계에 있어 성별차이 가 있는지를 알아봄으로써 연구 결과의 해석에 시사 점을 더하고자 한다.

가설 7. 성별에 따라 피해자 특성(공격성, 청결도, 비만도), 집단따돌림, 자아존중감, 우울감 변인 사이의 영향관계에 차이가 있을 것이 다.

\section{Research Method}

중학생들의 집단따돌림에 대한 선후행 변인간의 관계를 조사하기 위해 대구시에 위치한 한 중학교의 협조를 얻어 1,2 학년 남녀학생에 대한 전수조사를 실시하고, 3 학년 학생 중 설문조사 참여를 희망하는 학생들을 대상으로 조사를 실시하였다. 중학교 학생 을 연구대상으로 삼은 이유는 이 시기가 또래 집단의 영향력이 가장 크고, 집단 따돌림이 가장 자주 발생 되는 시기(Kim, 2005)이기 때문이다. 총 594명 학생 으로부터 설문응답을 얻었는데, 자신의 특성에 대한 주관적 평가를 바탕으로 설문에 응답하도록 하였다. 공격성을 측정하기 위해 Chung(2009)의 연구에서 발 췌한 4항목(친구들과 다툼이 잦다, 친구들에게 공격 적이다, 친구들에게 상처 주는 농담을 한다, 다름 사 람들을 놀리며 노는 것을 좋아한다)이 사용되었다. 청결성과 비만도에 대한 항목은 선행연구(Keery, Boutelle, van den Berg, \& Thompson, 2005)를 참조
하여 각 두 항목씩(청결성-내 외모는 늘 깨끗한 편이 다, 내 의상은 늘 청결한 편이다; 비만도-나는 뚱뚱하 다, 나는 비만이다) 사용되었다. 집단따돌림 피해에 대해서는 선행연구(Wang, Iannotti, \& Nansel, 2009) 를 참고하여 “나는 지난 3 개월 안에 학교에서 다른 친구들로부터 때리기, 발로 차기, 밀치기 중 하나를 당해본 적이 있다", "나는 지난 3 개월 안에 학교에서 다른 친구들로부터 안좋은 별명으로 불리기, 웃음거 리 되기, 괴롭힘 당하기" 중 하나를 당해본 적이 있 다", "나는 지난 3 개월 안에 학교에서 다른 친구들로 부터 외모에 대해 안좋은 지적 듣기를 당해본 적이 있다", "나는 지난 3 개월 안에 학교에서 다른 친구들 로부터 성격에 대해 안좋은 지적 듣기를 당해본 적이 있다", "나는 지난 3 개월 안에 학교에서 다른 친구들 로부터 무시당해본 적이 있다"의 5항목으로 측정되 었다. 자아존중감은 Rosenberg(1963)의 자아존중감 척도 10 개 항목, 우울감은 Beck, Steet, and Brown (1996)의 우울감 측정 척도 10 개 항목을 사용하였다. 각 항목은 전혀 그렇지 않다(1)-매우그렇다(6)의 6점 척도로 측정되었으며, 그 외에 성별, 학년, 가계소득 수준, 학업수준에 대해 명목척도로 측정되었다. 분석 을 위해 SPSS를 이용한 기술통계, $t$-test, 요인분석, $\mathrm{AMOS}$ 를 이용한 경로분석법이 사용되었다.

설문대상자의 인구통계적 특성을 살펴보면 남학생 이 190 명(32\%), 여학생이 404명(68\%)이었으며, 학년 으로는 1학년이 258명(43.4\%), 2학년이 290명(48.8 $\%$, 3 학년이 46 명 $(7.7 \%)$ 으로 나타났다. 응답자의 가 계소득수준은 낮음이 34 명(5.7\%), 중간이 478명(80.5 $\%$ ), 높음이 82명(13.8\%)으로 나타났으며, 학업 수준 의 경우에는 낮음이 127 명(21.4\%), 중간이 337 명 $(56.7 \%)$, 높음이 130 명(21.9\%)으로 나타났다.

\section{N. Results}

1. Exploratory factor analysis and means of research variables

연구변인에 대해 베리멕스 회전을 이용한 탐색적 요인분석을 실시하여 정리한 결과는 〈Table 1〉과 같 다. 아이겐 값 1 이상의 요인을 도출한 결과에 따르면 우울감은 7 개 항목, 자아존중감은 4 개 항목, 집단따돌 림은 5 개 항목, 공격성은 4 개 항목, 비만과 청결성은 
각각 2개 항목이 각 요인에 적재되었으며, 요인 적재 치는 .566 부터 .933 까지 분포되었다. 아이겐 값은 1.573 부터 4.188 까지 분포되었고, 총 누적 변량은 $66.584 \%$ 로 나타났으며, 6개 변인의 신뢰도는 .722부
터 .928까지 분포되었다.

각 변인의 평균값을 확인한 결과, 6점 척도 중 집 단따돌림은 1.366 정도로 나타나, 비교적 소수의 학 생 집단에서만 이러한 일들이 일어나고 있는 것을 알

<Table 1> Exploratory factor analysis results

\begin{tabular}{|c|c|c|c|c|c|c|}
\hline Factor & Item & $\begin{array}{l}\text { Factor } \\
\text { loading }\end{array}$ & $\begin{array}{l}\text { Eigen } \\
\text { value }\end{array}$ & $\begin{array}{l}\text { Variance } \\
(\%)\end{array}$ & $\begin{array}{l}\text { Cumulative } \\
\text { variance }(\%)\end{array}$ & $\begin{array}{l}\text { Cronbach's } \\
\text { alpha }\end{array}$ \\
\hline \multirow{7}{*}{ Depression } & I am not happy as the past. & .779 & \multirow{7}{*}{4.188} & \multirow{7}{*}{17.451} & \multirow{7}{*}{17.451} & \multirow{7}{*}{.875} \\
\hline & I get angry to myself. & .741 & & & & \\
\hline & I often cry. & .709 & & & & \\
\hline & I am easily annoyed and feel tiresome. & .733 & & & & \\
\hline & $\begin{array}{l}\text { I become having less interest on others compared } \\
\text { to the past. }\end{array}$ & .763 & & & & \\
\hline & It is hard to make a decision as the past. & .761 & & & & \\
\hline & I become having less appetite as the past. & .618 & & & & \\
\hline \multirow{5}{*}{ Be bullied } & $\begin{array}{l}\text { I suffered "hitting, kicking, and pushing" done by } \\
\text { friends in school within the last } 3 \text { months. }\end{array}$ & .759 & \multirow{5}{*}{3.134} & \multirow{5}{*}{13.057} & \multirow{5}{*}{30.509} & \multirow{5}{*}{.848} \\
\hline & $\begin{array}{l}\text { I suffered "calling by no good nicknames, joking, } \\
\text { and teasing" done by friends in school within the } \\
\text { last } 3 \text { months. }\end{array}$ & .835 & & & & \\
\hline & $\begin{array}{l}\text { I suffered "no good mentions on my appearance" } \\
\text { done by friends in school within the last } 3 \text { months. }\end{array}$ & .778 & & & & \\
\hline & $\begin{array}{l}\text { I suffered "no good mentions on my personality" } \\
\text { done by friends in school within the last } 3 \text { months. }\end{array}$ & .756 & & & & \\
\hline & $\begin{array}{l}\text { I suffered "ignoring" done by friends in school } \\
\text { within the last } 3 \text { months. }\end{array}$ & .721 & & & & \\
\hline \multirow{4}{*}{ Self-esteem } & $\begin{array}{l}\text { I think that I am a valuable person as much as } \\
\text { others. }\end{array}$ & .724 & \multirow{4}{*}{2.768} & \multirow{4}{*}{11.533} & \multirow{4}{*}{42.042} & \multirow{4}{*}{.852} \\
\hline & I can do well as much as most of others. & .780 & & & & \\
\hline & I have a positive attitude toward myself. & .781 & & & & \\
\hline & I am mostly satisfied with myself. & .790 & & & & \\
\hline \multirow{4}{*}{ Aggression } & I like to play by teasing others. & .566 & \multirow{4}{*}{2.385} & \multirow{4}{*}{9.938} & \multirow{4}{*}{51.980} & \multirow{4}{*}{.722} \\
\hline & I make a joke hurting my friends. & .792 & & & & \\
\hline & I am aggressive to my friends. & .829 & & & & \\
\hline & I often fight with my friends. & .741 & & & & \\
\hline \multirow{2}{*}{ Obesity } & I am fat. & .928 & \multirow{2}{*}{1.932} & \multirow{2}{*}{8.052} & \multirow{2}{*}{60.032} & \multirow{2}{*}{.928} \\
\hline & I am overweight. & .933 & & & & \\
\hline \multirow{2}{*}{ Cleanliness } & My appearance always tends to be clean. & .789 & \multirow{2}{*}{1.573} & \multirow{2}{*}{6.553} & \multirow{2}{*}{66.584} & \multirow{2}{*}{.754} \\
\hline & My clothes always tends to be clean. & .808 & & & & \\
\hline
\end{tabular}


<Table 2> Mean differences by genders

\begin{tabular}{c|c|c|c|c}
\hline \multirow{2}{*}{ Item } & \multicolumn{3}{|c|}{ Mean $(S D)$} & \multicolumn{1}{c}{$\begin{array}{c}t \\
(\text {-value } \\
\end{array}$} \\
\cline { 2 - 5 } & $\begin{array}{c}\text { Total } \\
(N=594)\end{array}$ & $\begin{array}{c}\text { Male } \\
(n=190)\end{array}$ & $\begin{array}{c}\text { Female } \\
(n=404)\end{array}$ \\
\hline \multirow{2}{*}{ Depression } & 2.343 & 2.085 & 2.464 \\
& $(1.140)$ & $(1.060)$ & $(1.157)$ & $-3.826^{* * *}$ \\
& 1.366 & 1.486 & 1.310 & $(.000)$ \\
\hline \multirow{2}{*}{ Be Bullied } & $(0.700)$ & $(0.809)$ & $(0.635)$ & $2.884^{* *}$ \\
& 4.947 & 4.983 & 4.931 & $(.004)$ \\
\hline \multirow{2}{*}{ Self-esteem } & $(0.862)$ & $(0.850)$ & $(0.869)$ & .688 \\
& 2.059 & 2.043 & 2.067 & $(.492)$ \\
\hline \multirow{2}{*}{ Aggression } & $(0.840)$ & $(0.879)$ & $(0.822)$ & -.317 \\
& 4.617 & 4.824 & 4.520 & $(.752)$ \\
\hline \multirow{2}{*}{ Obesity } & $(1.507)$ & $(1.429)$ & $(1.534)$ & $2.301^{*}$ \\
& 4.546 & 4.397 & 4.615 & $(.022)$ \\
\hline \multirow{2}{*}{ Cleanliness } & $(0.989)$ & $(0.941)$ & $(1.004)$ & $-2.514^{*}$ \\
& & & & $(.012)$ \\
\hline
\end{tabular}

수 있었으며, 우울감은 2.343 , 공격성은 2.059 수준으 로 중간값인 3.5 이하였으며, 자아존중감은 4.947 , 비 만도 4.617, 청결성 4.546 수준으로 중간값 이상으로 나타났다(Table 2). 중학생들은 전반적으로 우울감과 공격성은 낮은 편이지만, 자신이 청결하고 다소 비만 하다고 느끼는 경향이 있다고 해석할 수 있다. 연구 결과 해석 시 참고하기 위해 성별간 평균값 비교를 실시한 결과, 집단따돌림, 우울감, 비만도, 청결성에 서 성별간 차이가 나타났다. 남학생들이 여학생들보 다 집단따돌림을 더 많이 겪고 있으나, 여학생들이 남학생들에 비해 더 우울감이 높은 것으로 나타났다. 응답자 특성 부분에서는 여학생들은 자신이 청결하 다고 느끼는 수준이 남학생보다 더 높았으며, 반대로 남학생들은 자신이 비만이라고 느끼는 수준이 여학 생보다 더 높았다.

\section{Confirmatory factor analysis and AVE checks}

본 연구의 인과모형 분석에 앞서 모형에 포함된 잠 재변수들에 대한 확인적 요인분석(confirmatory factor analysis)을 실시하였다(Table 3). 확인적 요인분석 결과, $\mathrm{CMIN}$ 는 $656.637(D F=237)$ 이며, $\mathrm{Q}$ 값 $(\mathrm{CMIN} /$ $\mathrm{DF})$ 은 2.771로 기준 값인 3보다 낮게 나타나, 양호한 적합도를 보였다(Kim, 2010). CFI는 .937, IFI는 .937, RMSEA는 .055로 Hair, Black, Babin, Anderson, and
Tatham(2006)이 제시한 적합도 기준인 .90 이상을 충 족하였다. 모든 관측변수들은 잠재변수에 대해 높은 경로계수를 보였는데, 경로계수의 C.R. 값은 8.725 부 터 16.940 까지 분포되어 모두 기준값 2 이상 $(p<.05)$ 상회하므로 통계적으로 유의하였다. 또한 판별타당성 을 검증하기 위해 잠재변수 간 평균분산추출값(AVE) 을 계산하였다. 결과에서 각 변인에 대한 평균분산추 출값이 상관관계 제곱 값보다 크게 나타나 잠재변인 의 판별타당성이 확인되었으므로(Fornell \& Larcker, 1981)(Table 4), 본 모형에 대하여 AMOS를 이용한 경로분석을 실시하였다.

\section{Causal relationships among research variables}

\section{1) Causal relationships among variables}

모든 응답자 데이터를 사용하여 경로분석을 실시 한 결과는 〈Fig. 1〉에 정리되었다. 모형적합도에서 $\mathrm{CMIN}$ 는 821.434( $D F=243)$ 이며, Q값(CMIN/DF)은 3.380 으로 기준 값인 3 에 근접하게 나타났으며, $\mathrm{CFI}$ 는 .913, IFI는 .914, RMSEA는 .063으로 양호하게 나타 났다. 결과에서 응답자의 특성 중 공격성, 청결성, 비 만도의 세 가지 요인은 상호 인과관계가 $\mathrm{CR}$ 값 2 이 상으로 높게 나타났으며, 공격성과 청결도는 부(-)적, 공격성과 비만도는 정(+)적, 청결성과 비만도는 부적 
$<$ Table 3> Confirmatory factor analysis results

\begin{tabular}{|c|c|c|c|c|}
\hline Path & $\begin{array}{l}\text { Standard } \\
\text { estimate }\end{array}$ & $\begin{array}{l}\text { Standard } \\
\text { error }\end{array}$ & $\begin{array}{c}\text { C.R. } \\
\text { (p-value) }\end{array}$ & Fit \\
\hline Aggression $1 \leftarrow$ Aggression & .688 & - & - & \multirow{24}{*}{$\begin{array}{c}\chi^{2}=656.637 \\
d f=237 \\
\mathrm{CMIN} / d f=2.771 \\
\mathrm{IFI}=.937 \\
\mathrm{TLI}=.927 \\
\mathrm{CFI}=.937 \\
\mathrm{RMSEA}=.055\end{array}$} \\
\hline Aggression $2 \leftarrow$ Aggression & .834 & .070 & $15.059^{* * *}(.000)$ & \\
\hline Aggression $3 \leftarrow$ Aggression & .709 & .054 & $14.317^{* * *}(.000)$ & \\
\hline Aggression $4 \leftarrow$ Aggression & .406 & .075 & $8.725^{* * *}(.000)$ & \\
\hline Cleanliness $1 \leftarrow$ Cleanliness & .725 & - & - & \\
\hline Cleanliness $2 \leftarrow$ Cleanliness & .841 & .111 & $11.891^{* * *}(.000)$ & \\
\hline Obesity $1 \leftarrow$ Obesity & .879 & - & - & \\
\hline Obesity $2 \leftarrow$ Obesity & .985 & .071 & $16.480^{* * *}(.000)$ & \\
\hline Bullied $1 \leftarrow$ Bullied & .654 & - & - & \\
\hline Bullied $2 \leftarrow$ Bullied & .753 & .070 & $15.047^{* * *}(.000)$ & \\
\hline Bullied $3 \leftarrow$ Bullied & .744 & .079 & $14.924^{* * *}(.000)$ & \\
\hline Bullied $4 \leftarrow$ Bullied & .760 & .075 & $15.155^{* * *}(.000)$ & \\
\hline Bullied $5 \leftarrow$ Bullied & .729 & .069 & $14.694^{* * *}(.000)$ & \\
\hline Self-esteem $1 \leftarrow$ Self-esteem & .619 & - & - & \\
\hline Self-esteem $2 \leftarrow$ Self-esteem & .624 & .088 & $13.010^{* * *}(.000)$ & \\
\hline Self-esteem $3 \leftarrow$ Self-esteem & .895 & .097 & $16.809^{* * *}(.000)$ & \\
\hline Self-esteem $4 \leftarrow$ Self-esteem & .914 & .097 & $16.940^{* * *}(.000)$ & \\
\hline Depression $1 \leftarrow$ Depression & .508 & - & - & \\
\hline Depression $2 \leftarrow$ Depression & .758 & .127 & $11.985^{* * *}(.000)$ & \\
\hline Depression $3 \leftarrow$ Depression & .726 & .141 & $11.740^{* * *}(.000)$ & \\
\hline Depression $4 \leftarrow$ Depression & .677 & .114 & $11.332^{* * *}(.000)$ & \\
\hline Depression $5 \leftarrow$ Depression & .753 & .124 & $11.947^{* * *}(.000)$ & \\
\hline Depression $6 \leftarrow$ Depression & .768 & .137 & $12.059^{* * *}(.000)$ & \\
\hline Depression $7 \leftarrow$ Depression & .764 & .143 & $12.029^{* * *}(.000)$ & \\
\hline
\end{tabular}

$<$ Table 4> AVE and squared correlations of research variables

\begin{tabular}{c|c|c|c|c|c|c}
\hline & Aggression & Cleanliness & Obesity & Be bullied & Self-esteem & Depression \\
\hline Aggression & .892 & & & & & \\
\hline Cleanliness & .061 & .902 & & & & \\
\hline Obesity & .023 & .120 & .878 & & & \\
\hline Be bullied & .097 & .036 & .026 & .952 & & \\
\hline Self-esteem & .066 & .292 & .038 & .069 & .951 & \\
\hline Depression & .102 & .085 & .080 & .130 & .287 & .873 \\
\hline CR & .969 & .948 & .935 & .990 & .987 & .979
\end{tabular}

AVE values were indicated in diagonal lines.

Squared correlations between variables were indicated under diagonal lines. 
(-) 상관성을 보였다. 이는 비만도가 높을수록 청결하 지 못하고, 비만도가 높을수록 공격성이 높으며, 청결 하지 못할수록 공격성도 높다는 것을 의미한다.

인과관계분석 결과에서는 공격성, 청결성, 비만도 세 가지 응답자 특성 모두 집단따돌림에 영향을 미치 는 요인으로 나타났는데, 응답자의 공격성이 높을수 록 $(\mathrm{CR}=5.423, p<.001)$, 청결도가 낮을수록 $(\mathrm{CR}=-2.029$, $p=.042)$, 비만도가 높을수록 $(\mathrm{CR}=2.062, p=.039)$ 집단 따돌림을 당하는 경우가 많은 것을 알 수 있었다. 또 한 집단따돌림은 자아존중감에 부적 영향 $(\mathrm{CR}=$ $-5.712, p<.001)$ 을, 우울감에 정적 영향 $(\mathrm{CR}=5.203$, $p<.001)$ 을 미쳤으며, 자아존중감과 우울감 사이에도 부적 인과관계 $(\mathrm{CR}=-7.993, p<.001)$ 가 확인되었다. 이 는 집단따돌림을 많이 당할수록 자아존중감이 낮아 지고, 우울감은 높아진다는 것을 의미한다. 이로서 가 설 $1,2,3,4,5,6$ 이 지지되었다.

\section{2) Gender differences in causal relationships} among variables

응답자의 성별에 따라 경로값에 차이가 있는지를 확인하기 위하여 집단비교분석을 실시하였으며, 결과 는 〈Fig. 2〉에 정리되었다. 모형적합도에서 $\mathrm{CMIN}$ 는 $1,113.626(D F=486)$ 이며, $\mathrm{Q}$ 값(CMIN/DF)은 2.291로 기준 값인 3 이하로 나타나 양호하였으며, CFI는 .908 , IFI는 .909, RMSEA는 .047로 양호하게 나타났 다. 먼저 응답자의 특성 중 공격성, 청결성, 비만도의 세 가지 요인간 인과관계를 살펴본 결과, 남자 중학
생 모델에서는 이 세 변인간 상호 인과관계가 유의하 지 않았으나, 여자 중학생 모델에서는 세 변인간 상 호 인과관계가 $\mathrm{CR}$ 값 2 이상으로 모두 높게 나타났다. 즉, 남자 중학생의 경우에는 공격성, 청결성, 비만도 가 독립적인 특성인 것으로 보이지만, 여자 중학생의 경우에는 비만도가 높을수록 청결하지 못하고 공격 성도 높으며, 청결하지 못할수록 공격성도 높다고 해 석할 수 있다.

남자 중학생과 여자 중학생 인과관계 모형 비교에 서 유의한 경로에 차이가 있었다. 먼저 남자 중학생 의 경우에는 응답자 특성 중 공격성 $(\mathrm{CR}=2.337, p<$ $.001)$ 과 청결도 $(\mathrm{CR}=-2.749, p<.001)$ 만이 집단따돌림 에 영향을 미치는 요인이었으나, 여자 중학생의 경우 에는 공격성 $(\mathrm{CR}=5.329, p<.001)$ 과 비만도 $(\mathrm{CR}=2.307$, $p<.001$ 만이 집단따돌림에 영향을 미치는 요인이었 다. 집단따돌림 후행 변인간의 인과관계에서는 남자 중학생과 여자 중학생의 차이가 없이 두 집단 모두에 서 집단따돌림이 높을수록 자아존중감은 낮고, 우울 감은 높게 나타났으며, 자아존중감이 낮을수록 우울 감이 높게 나타났다.

두 성별간의 집단모형비교를 통해 각 경로가 두 성 별간에 통계적으로 유의한 수준의 차이를 보이는지 를 알아보기 위해 Critical ratio for difference의 수치 를 확인하였는데, 모형에서 제시한 경로 중 '청결성 이 집단따돌림에 미치는 영향관계의 경로' 하나에서 기준값 2 이상 (Critical ratio for difference $=2.710)$ 으 로 유의한 차이를 보였다. 이를 통해 청결성과 집단

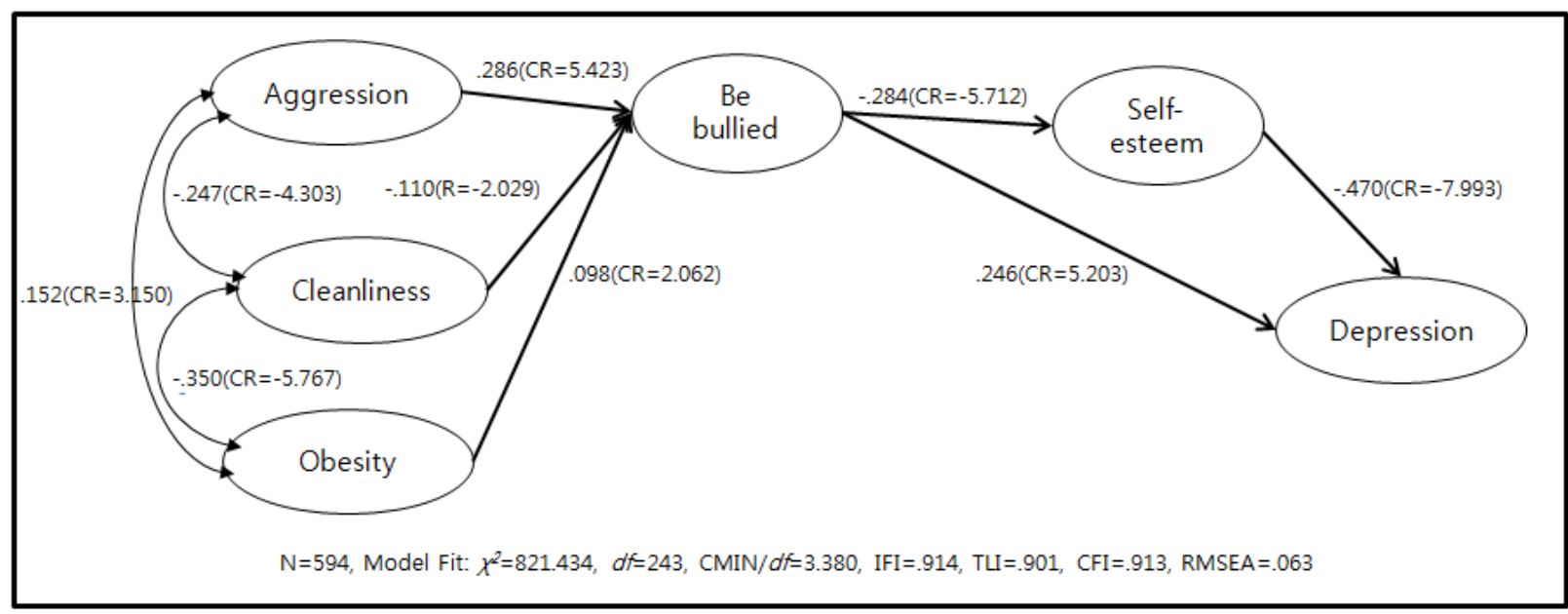

<Fig. 1> Causal relationships among variables 


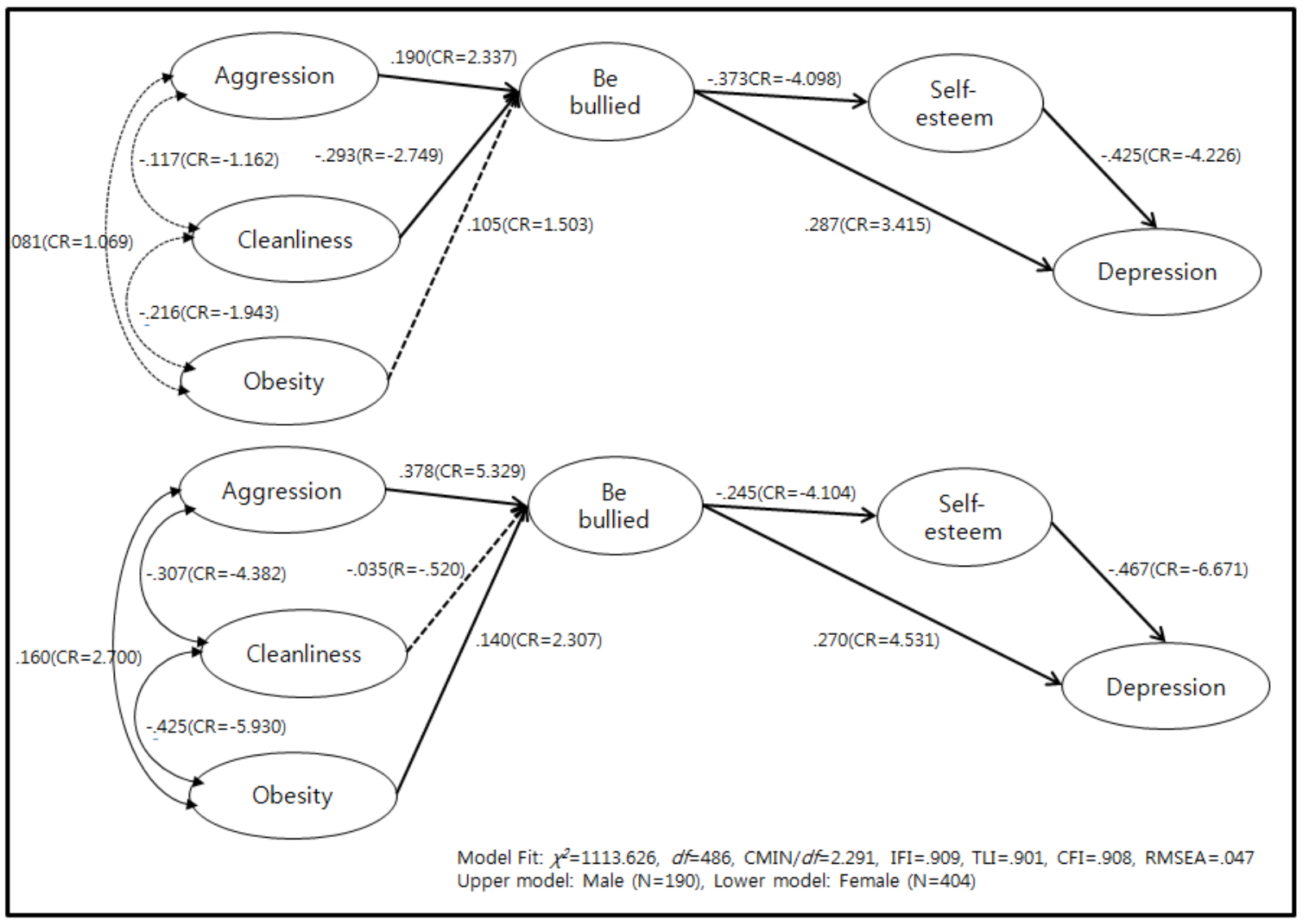

<Fig. 2> Gender differences in causal relationships among variables

따돌림의 부적관계 경로에 대해서는 남자와 여자 중 학생간 유의한 차이가 있다고 말할 수 있다. 비만도 와 집단따돌림의 정적 관계 경로의 성별차이는 통계 적으로 유의한 수준은 아니었다. 이로서 '성별에 따 라 피해자특성, 집단따돌림, 자아존중감, 우울감 변인 사이의 경향관계에 차이가 있을 것이다, 라고 제시한 가설 7 은 부분적으로 지지되었다.

\section{Conclusion}

본 연구의 목적은 중학생을 대상으로 집단따돌림 의 선행 변인 중 피해자 성격 및 외모 특성의 영향에 대해 알아보고, 집단따돌림의 선후행 변인에 대한 관 계모형을 검증하는 것이었다. 주요 연구 결과와 시사 점은 다음과 같다.

첫째, 중학생 집단따돌림 피해자 특성 중 공격성, 비만도, 청결성은 집단따돌림 유발에 영향을 미치는 변인인 것으로 확인되었다. 중학생의 공격성이 높을
수록, 비만도가 높을수록, 청결하지 못할수록 집단따 돌림의 피해를 받기 쉬운 것으로 나타났다. 공격성과 집단따돌림의 관계 결과는 선행연구(Chung, 2009; Lee, 1999; Olweus, 1994)와 일관되었으며, 성격 특성 중 공격성이 집단따돌림의 가해자 특성뿐만 아니라, 피해자 특성 중 하나라는 것을 다시 한번 확인한 결 과이다. 공격성이 높을수록 또래 친구들로부터 외면 받기 쉽고, 이것이 따돌림으로 이어진다고 추론할 수 있다. 비만도와 집단따돌림간의 인과관계는 선행연구 (Barnett et al., 2010; Lumeng et al., 2010)에서 제시 된 것과 일관되었으며, 이와 관련하여 실증자료가 부 족한 상황에서 중학생을 대상으로 실증결과를 얻었 다는데 의의가 있다. 또한 청결도와 집단따돌림간의 관계는 따돌림 피해예방 지침서 등에서 다루어지고 있으나, 관련한 실증연구가 부족하였는데, 본 연구에 서 실증결과를 얻어 후속 연구를 위한 토대를 마련했 다고 볼 수 있다.

둘째, 집단따돌림의 피해 수준은 피해자의 자아존 
중감에 부적 영향을 미치고, 우울감에 정적 영향을 미치며, 자아존중감은 다시 우울감에 부적 영향을 미 치는 관계를 보였다. 집단따돌림과 자아존중감간의 관계는 해외에서 수행된 연구들(Gini, 2008; Olweus, 1994; Ranta et al., 2009)과 일관되었는데, 이는 해외 자료들에서 증명된 관계가 국내 중학생 집단에서도 동일하게 나타났다는 것을 보여주는 결과이다. 한편, 집단따돌림과 우울감의 관계는 선행연구(Choi, 2009; Moon, 2014)와 일관된 것이었으며, 자아존중감과 우 울감의 부적 관계는 또 다른 선행연구들(Callaghan \& Joseph, 1995; Lee, 2003)에서 제시된 것과 일관되었 다. 결과적으로 집단따돌림을 받은 학생들은 자아존 중감이 낮아졌으며, 우울감은 높아져 집단따돌림이 피해자들에게 심리학적, 병리학적으로 부정적 영향을 미친다고 할 수 있다.

셋째, 중학생 집단의 성별에 따라 집단따돌림 선후 행 변인간의 관계에 차이가 있는지를 알아보았다. 남 자 중학생의 경우, 피해자의 공격성과 청결성이 집단 따돌림에 영향을 주는 변인이었으나, 여자 중학생의 경우에는 피해자의 공격성과 비만도가 집단따돌림에 영향을 주는 변인이었다. 통계적으로 경로의 유의성 에 있어 성별차이가 나타나는지를 확인한 결과에 따 르면, 청결성-집단따돌림의 관계에서만 유의한 차이 가 나타났다. 이를 해석하면 피해자의 청결성 요인이 집단따돌림 유발에 영향을 미치는 정도에 있어 남녀 차이가 있는데, 여학생에 비해 남학생의 경우 청결성 이 집단따돌림에 미치는 영향이 더 강하게 나타난다 고 할 수 있다. 이는 앞선 평균값 비교에서 나타났듯 이, 남학생이 여학생보다 청결도가 더 낮은 반면, 집 단따돌림 수준은 더 높아서 그 차이로 인해 더 명확 한 영향성이 나타난 결과라고 해석해 볼 수 있다. 그 외에 집단따돌림-자아존중감-우울감 사이의 영향관계 에 있어서는 성별 차이가 나타나지 않았다. 이는 성 별과 상관없이 이 세가지 변인간의 관계가 명확히 드 러난다는 것을 보여준다. 집단따돌림의 선·후행 변 인간의 관계 연구에서 성별 차이를 비교한 사례는 발 견되지 않았다. 본 연구의 결과를 토대로 후속 연구 에서는 더 다양한 변인에 대한 성별 차이 연구 시도 가 수행된다면 더 의미있는 결과들을 얻을 수 있을 것이다.

본 연구는 사회적 문제로 대두된 학교 내 집단따돌
림의 원인 중 주요 변인으로 다루어져 왔던 피해자의 성격 요인 외에 외모 요인의 중요성을 제시하고, 이 의 영향성을 검증하고자 하였다. 피해자의 성격 요인 중 공격성과 외모요인 중 청결성과 비만도의 영향성 에 집중하여 이 요인들이 집단따돌림의 원인이 된다 는 것을 확인하였고, 집단따돌림의 피해는 다시 자아 존중감을 낮추고, 우울감을 높이는 등 부정적 영향을 미치는 결과를 확인하였다. 이처럼 집단따돌림 피해 자 특성이 집단따돌림, 사회심리적 그리고 병리적 피 해로 이어지는 인과관계에 대한 연구모형을 개발하 고 검증한 결과는 해당 문제에 대한 이해를 높이고, 피해자, 방관자, 가해자의 멘토링/교화/치료 프로그램 개발 시 주요 기초자료로 활용될 수 있을 것이다. 또 한 남학생의 경우, 청결성 관리에 대한 교육을 더욱 강화한다면 또래 집단에서의 수용성을 더 높이고, 집 단따돌림 피해를 예방하는데 부분적으로 나마 기여 하는 바 있을 것이다.

본 연구는 사회학, 심리학, 의학, 의류학 등 다양한 분야에서 다양한 관점으로 전개되어 왔던 이론과 주 장을 연계하여 이를 하나의 인과모형으로 개발하고 통합적으로 검증했다는 점에서 기존 학문 분야의 관 점과 시각을 넓히는데 기여할 수 있을 것이며, 다양 한 논점을 제시할 수 있을 것으로 여겨진다. 부분적 인 변인들 간의 관계들은 검증되어 왔지만, 큰 틀에 서 인과관계를 연구하는 것은 변인들 간의 통합적 관 계를 더 상세히 이해할 수 있다는 점에서 관련 분야 의 담론을 활성화 시키는 데 기여할 수 있을 것으로 기대한다. 여기서 개발된 연구모형은 후속연구의 틀 로 활용되어 관련 연구를 활성화 시키는데 보탬이 되 리라 사료된다.

본 연구의 가장 큰 제한점은 연구 대상이 한 지역 의 한 중학교 학생들에 국한되었다는 점이다. 이런 한계를 극복하고자 1 2학년 전수대상 조사를 실시 하였으나, 해석의 확대에는 주의를 기울여야 할 것이 며, 향후 더 많은 지역의 더 많은 학교를 대상으로 자 료수집을 하여 가설 검증을 실시한다면 더 의미있는 결과를 얻을 수 있을 것이라 생각한다. 또한 선행연 구와 자료에서 제시되었던 집단따돌림 피해자 요인 중 지나치게 내성적 성격, 신체 및 지적장애, 좋지 않 은 인상, 지나치게 튀는 외모 등 다양한 요인들의 영 향성도 고려할 수 있을 것이다. 집단따돌림 피해자의 
성격요인과 외모요인의 하부차원에 대한 더 심도깊 은 후속연구들이 진행된다면 해당 주제에 대한 이해 의 폭을 넓히고, 더 의미있는 시사점을 얻는데 큰 도 움이 되리라 생각한다.

\section{References}

Andreou, E., \& Bonoti, F. (2010). Children's bullying experiences expressed through drawings and self-reports. School Psychology International, 31 (2), 164-177. doi:10.1177/0143034309352421

Archer, J. (2004). Sex differences in aggression in realworld settings: A meta-analytic review. Review of General Psychology, 8(4), 291-322. doi:10. 1037/1089-2680.8.4.291

Barnett, M. A., Livengood, J. L., Sonnentag, T. L., Barlett, N. D., \& Witham, R. Y. (2010). Children's anticipated responses to hypothetical peers with undesirable characteristics: Role of peers' desire to change, effort to change, and outcome. The Journal of Genetic Psychology, 171(3), 262269. doi:10.1080/00221325.2010.492815

Beck, A. T., Steer, R. A., \& Brown, G. K. (1996). Manual for the beck depression inventory-II. San Antonio, TX: Psychological Corporation.

Brehm, S. S., \& Kassin, S. M. (1990). Social Psychology. Boston, MA: Houghcon Mifflin.

Bullying. (2009). In Special education dictionary. Retrieved January 24, 2017, from http://terms.naver. com/entry.nhn?docId $=384153 \&$ mobile $\&$ cid $=42128$ \&categoryId $=42128$

Callaghan, S., \& Joseph, S. (1995). Self-concept and peer victimization among schoolchildren. Personality and Individual Differences, 18(1), 161163. doi:10.1016/0191-8869(94)00127-E

Centers for Disease Control \& Prevention. (2014, October 22). 제 10 차 청소년 건강행태 온라인조 사 결과발표 [The $10^{\text {th }}$ adolescent health status online research result presentation]. Retrieved March 20, 2015, from https://yhs.cdc.go.kr

Choi, J.-A. (2009). Understanding the relationship between relational victimization and depression in early adolescence based on stress-coping theory: A focus on cognitive factors and coping strategies. Studies on Korean Youth, 20(2), 383410.

Chung, I.-J. (2009). Dynamic relationships of poverty and delinquency trajectories. Korean Journal of Child Studies, 30(3), 113-125.

Chung, J. H. (2011, December 28). 왕따의 뿌리 [Roots of bullying]. Hankook-ilbo, Retrieved January 24, 2017, from http://www.hankookilbo. com/v/28a068bf769d42e5a4c63c994c69a0f4

Craig, W., Harel-Fisch, Y., Fogel-Grinvald, H., Dostaler, S., Hetland, J., Simons-Morton, B., ... \& Pickett, W. (2009). A cross-national profile of bullying and victimization among adolescents in 40 countries. International Journal of Public Health, 54(2), 216-224. doi:10.1007/s00038-0095413-9

Fornell, C., \& Larcker, D. F. (1981). Evaluating structural equation models with unobservable variables and measurement error. Journal of Marketing Research, 18(1), 39-50. doi:10.2307/ 3151312

Gini, G. (2008). Associations among overt and relational victimization and adolescents' satisfaction with friends: The moderating role of the need for affective relationships with friends. Journal of Youth and Adolescence, 37(7), 812-820. doi:10. 1007/s10964-007-9236-9

Hair, J. F., Black, W. C., Babin, B. J., Anderson, R. E., \& Tatham, R. L. (2006). Multivariate data analysis (6th ed.). Upper Saddle River, NJ: Pearson Prentice Hall.

Jacobs, J. E., Lanza, S., Osgood, D. W., Eccles, J. S., \& Wigfield, A. (2002). Changes in children's self-competence and values: Gender and domain differences across grades one through twelve. Child Development, 73(2), 509-527. doi:10.1111/ 1467-8624.00421

Jeong, J. Y. (2013). The influence of the dysfunc- 
tional attitude of highschool students on depression: Mediating effects of stress-coping selfesteem. Unpublished master's thesis, Kyungsung University, Busan, Korea.

Keery, H., Boutelle, K., van den Berg, P., \& Thompson, J. K. (2005). The impact of appearancerelated teasing by family members. Journal of Adolescent Health, 37(2), 120-127. doi:10.1016/ j.jadohealth.2004.08.015

Kim, J.-Y., \& Chung, Y.-K. (2007). Impact of school violence on depression: Moderating effect of family factors. Korean Journal of Family Social Work, 19, 5-28.

Kim, K. S. (2010). AMOS 18.0 구조방적싱 모형 분석 [AMOS 18.0 structural equation model analysis]. Seoul: Hannarae.

Kim, K.-S., \& Koo, K.-J. (2016). Effect of leisure activities on bullying and school life adjustment among the middle school students. Journal of Sport and Leisure Studies, 66, 509-520.

Kim, O.-S., Kim, S.-W., \& Kim, A.-J. (2002). BMI, weight control behavior, and self-esteem in high school adolescents. The Journal of Korean Academic Society of Adult Nursing, 14(1), 53-61.

Kim, S.-H. (2005). A study on the causes and problems of group bullying in elementary schools. Unpublished master's thesis, Joongbu University, Chungcheongnam-do, Korea.

Kim, Y. A. (2000). 자기성장프로그램이 대인관계 및 자아존중감에 미치는 효과 [The effect of selfgrowth programs on personal relationships and self-esteem]. Unpublished master's thesis, Konkuk University, Seoul, Korea.

Kim, Y. T., \& Park, H. S. (1997). 청소년 친구 따돌 림의 실태 조사 [Study on Adolescents' bullying]. In Adolescent Counseling Plaza (Ed..), 청소년상 담문제 연구보고서: Vol. 29. 따돌리는 아이들, 따돌림 당하는 아이들 [Adolescents Counseling Problem Research Report] (pp. 55-84). Seoul: Adolescent Conversation Plaza.

Koo, B. Y. (1997). 청소년 집단 따돌림의 원인과 지
도방안 [Causes of and guides for adolescents bullying]. In Adolescents Counseling Plaza (Ed.), 청소년상담문제 연구보고서: Vol. 29. 따돌리는 아이들, 따돌림 당하는 아이들 [Adolescents Counseling Problem Research Report] (pp. 7-35). Seoul: Adolescent Conversation Plaza.

Leahy, R. L., Holland, S. J., \& McGinn, L. K. (2011). Treatment plans and interventions for depression and anxiety disorders (2nd ed.). New York: Guilford Publications.

Lee, H. J., Wi, S. A., \& Kim, B. J. (2015). A study of aggression and delinquent behavior: Focusing on gender difference and change. The Korean Journal of Woman Psychology, 20(4), 675-695.

Lee, K. M., \& Kim, J. H. (1999). 혹시 우리아이 왕 따가 아닐까? [Is my kid an outcast by chance?]. Seoul: Kookil Media.

Lee, M.-H. (2009). A study on the relationship between interest in appearance, appearance satisfaction and life satisfaction in adolescents. Journal of the Korean Society of Costume, 59(8), 97-109.

Lee, S.-J. (2003). The relationship between behavioral and psychological characteristic of bullying the child. Studies on Korean Youth, 14(2), 121-146

Lee, S. G. (1999). Predicting peer rejection of middle-school students with ordered probit analysis. Korean Journal of Social Welfare, 37, 357-379.

Lee, S. M. (1995). The influence of peer status and school achievement in middle school student's delinquency. Unpublished master's thesis, Ewha Womans University, Seoul, Korea.

Loeber, R., \& Stouthamer-Loeber, M. (1998). Development of juvenile aggression and violence: Some common misconceptions and controversies. American Psychologist, 53(2), 242-259. doi:10. 1037/0003-066X.53.2.242

Lumeng, J. C., Castle, V. P., \& Lumeng, C. N. (2010). The role of pediatricians in the coordinated national effort to address childhood obesity. $P e$ - 
diatrics, 126(3), 574-575. doi:10.1542/peds.20101873

Lund, R., Nielsen, K., Hansen, D., Molbo, D., Christensen, U., Due, P., et al., (2009). Exposure to bullying at school and depression in adulthood: A study of Danish men born in 1953. European Journal of Public Health, 19(1), 111-116.

Lund, R., Nielsen, K. K., Hansen, D. H., Kriegbaum, M., Molbo, D., Due, P., \& Christensen, U. (2009). Exposure to bullying at school and depression in adulthood: A study of Danish men born in 1953. European Journal of Public Health, 19(1), 111116. doi:10.1093/eurpub/ckn101

Mc Guckin, C., Cummins, P. K., \& Lewis, C. A. (2008). Bully/victim problems in Northern Ireland's schools: Data from the 2000 "Young persons' Behavior and Attitude Survey". Individual Differences Research, 6(4), 280-288.

Moon, Y.-S. (2014). A phenomenological study on the psychological distress of damaged youth by bullying in group. Unpublished master's thesis, Kyungbuk University of Foreign Studies, Daegu, Korea.

Mussen, P. H., Conger, J. J., Kagan, J., \& Huston, A. C. (1984). Child development and personality (6th ed.). New York: Harper \& Row.

National Youth Policy Institute. (2010). 2009 한국 아 동 청소년 비만실태조사 [Korea survey on the obesity of youth and children in 2009]. Seoul: National Youth Policy Institute.

Olweus, D. (1994). Bullying at school: Basic facts and effects of a school based intervention program. Journal of Child Psychology and Psychiatry, 35(7), 1171-1190. doi:10.1111/j.14697610.1994.tb01229.x

Oversea Economic Team. (2017, January 14). 미국도 들끓는 왕따 문제, 법적 처벌 논란 [Bullying problems swarmed in the US, controversy on legal punishment]. Economic Review, Retrieved January 24, 2017, from http://www.econovill. com/news/articleView.html?idxno=306261
Park, S. K., \& Chung, M. K. (2014). A study of elementary school students' living habits by grade and gender: Focused on cleanliness and Organization. Journal of Korean Practical Arts Education, 20(3), 41-65.

Ranta, K., Kaltiala-Heino, R., Pelkonen, M., \& Marttunen, M. (2009). Associations between peer victimization, self-reported depression and social phobia among adolescents: The role of comorbidity. Journal of Adolescence, 32(1), 77-93. doi: 10.1016/j.adolescence.2007.11.005

Rosenberg, M. (1965). Society and the adolescent self-image. Princeton, NJ: Princeton University Press.

Samples, F., \& Aber, L. (1998). Evaluations of school-based violence prevention programs. In D. S. Elliott, B. A. Hamburg, \& K. R. Williams (Eds.), Violence in American schools: A new perspective (pp. 217-252). Cambridge, UK: Cambridge University Press.

Seo, Y. K. (2003). Relationships between adolescents' appearance satisfaction and self-esteem and academic achievement. Unpublished master's thesis, Sookmyung Womens' University, Seoul, Korea.

Shin, B. R. (2016, December 2). 암 이겨낸 11살 소 녀, 급우들 왕따 못버티고 자살 [An 11 year-old girl overcome a cancer, suicided due to bullying of classmates]. Korea Daily News. Retrieved January 24, 2017, from http://www.koreadaily. com/news/read.asp?art_id $=4732115$

Sim, H.-O. (2007). A cross-sectional and longitudinal study on bullying/victimization and overt/relational aggression: Focused on gender. Korean Journal of Human Ecology, 16(6), 1107-1118.

Skrzypiec, G., Slee, P., Murray-Harvey, R., \& Pereira, B. (2011). School bullying by one or more ways: Does it matter and how do students cope? School Psychology International, 32(3), 288-311. doi:10.1177/0143034311402308

Statistics Korea. (2010). 2010 사회조사보고서 [Report 
on the social survey]. Retrieved January 24, 2017, from http://kosis.kr/ups/ups_01List.jsp?pubcode= $\mathrm{KN}$

Sweetingham, R., \& Waller, G. (2008). Childhood experiences of being bullied and teased in the eating disorders. European Eating Disorders Review, 16(5), 401-407. doi:10.1002/erv.839

The Foundation for Preventing Youth Violence. (1999). 집단 따돌림의 실태와 대처방안 [Status and preparation plan]. Seoul: The Foundation for Preventing Youth Violence.

The Korean Federation of Teachers' Association. (1999). 집단 따돌림(왕따) 무엇이 문제인가?: '99년도 제 2차 교육개혁 대토론회 [What are problems for bullying: The $2^{\text {nd }}$ education reform discussion].
Seoul: Korea National University of Education the Center for in-service education.

Wang, J., Iannotti, R. J., \& Nansel, T. R. (2009). School bullying among adolescents in the United States: Physical, verbal, relational, and cyber. Journal of Adolescent Health, 45(4), 368-375. doi:10.1016/j.jadohealth.2009.03.021

Wei, H.-S., \& Jonson-Reid, M. (2011). Friends can hurt you: Examining the coexistence of friendship and bullying among early adolescents. School Psychology International, 32(3), 244-262. doi: 10.1177/0143034311402310

Yoo, J.-J., \& Johnson, K. K. P. (2007). Effects of appearance-related testing on ethnically diverse adolescent girls. Adolescence, 42(166), 353-380. 